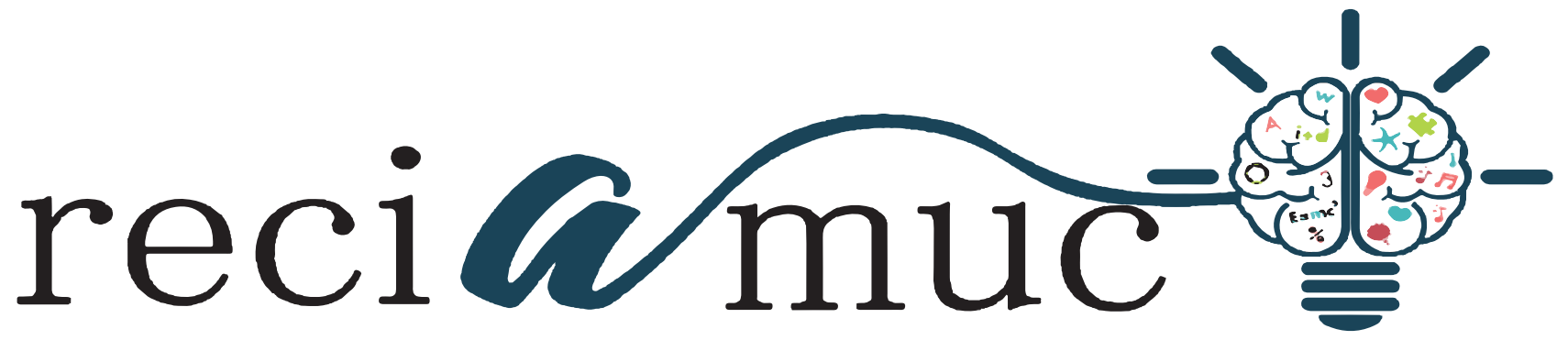

DOI: 10.26820/reciamuc/4.(4). diciembre.2020.113-124

URL: https://reciamuc.com/index.php/RECIAMUC/article/view/575

EDITORIAL: Saberes del Conocimiento

REVISTA: RECIAMUC

ISSN: 2588-0748

TIPO DE INVESTIGACIÓN: Artículo de Revisión

CóDIGo UNESCO: 32 Ciencias Médicas; 3201 Ciencias Clínicas

PAGINAS: 113-124

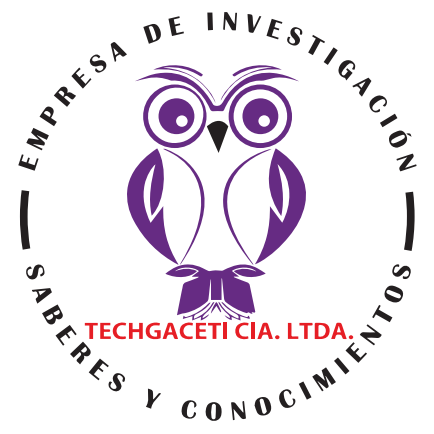

\title{
Helicobacter Pylori, esquemas de tratamiento y su efectividad en la actualidad
}

Helicobacter Pylori, treatment schemes and their effectiveness today Helicobacter Pylori, esquemas de tratamento e a sua eficácia nos dias de hoje Javier David Lara Icaza'; Castula Tania Triana Castro2; Alisheth Fuenmayor Boscán ${ }^{3}$

RECIBIDO: 23/09/2020 ACEPTADO: 17/10/2020 PUBLICADO: 24/12/2020

1. Magister en Microbiología Mención Biomédica; Licenciado en Laboratorio Clínico; Investigador Independiente; Universidad de Guayaquil; Guayaquil, Ecuador; javier.lara.icaza@hotmail.com; https://orcid.org/0000-00031397-4915

2. Especialista en Anatomía Patológica; Doctora en Medicina y Cirugía; Investigadora Independiente; Universidad Católica de Santiago de Guayaquil; Guayaquil, Ecuador; castula.triana@cu.ucsg.edu.ec; https://orcid. org/0000-0002-6271-9761

3. Doctora en Inmunología; Investigadora Independiente; alisbethdfb@gmail.com; https://orcid.org/0000-00019879-2373

\section{CORRESPONDENCIA \\ Javier David Lara Icaza \\ javier.lara.icaza@hotmail.com}

Guayaquil, Ecuador

() RECIAMUC; Editorial Saberes del Conocimiento, 2020 


\section{RESUMEN}

En la actualidad, la infección por Helicobacter pylori se sigue considerando una de las infecciones bacterianas crónicas que se presentan con mayor frecuencia en la población mundial. Asimismo, se reconoce por la severidad de sus consecuencias y lo complejo que puede ser su manejo terapéutico. El objetivo del presente estudio consiste en plasmar los principales esquemas de tratamiento del $\mathrm{H}$. pylori y su efectividad en la actualidad. Asimismo, se hace referencia a la resistencia antibiótica, situación en el Ecuador y las posibles alternativas de tratamiento para el futuro. El modelo de investigación es una revisión de tipo documental bibliográfico. Se encontró que los esquemas de tratamiento clasificados según la combinación de los fármacos pueden ser: cuádruple, híbrida, concomitante y triple. Mientras que, según el momento de su aplicación se pueden clasificar en tratamiento de primera, segunda, tercera y cuarta línea. La terapia cuádruple es considerada una de las mejores terapias iniciales, especialmente en áreas donde la tasa de resistencia a la claritromicina es $>15 \%$. Por su parte, la terapia híbrida tiene una eficacia del $90 \%$, incluso comparándolos con terapias cuádruples con bismuto. Algunos autores coinciden en que la terapia concomitante tiene una efectividad global de 88-90\%. Por último, la tasa de resistencia a la claritromicina ha ido en aumento, razón por la cual se hace cada vez más probable el fracaso de la terapia triple. En consecuencia, cada esquema debe elegirse de manera individualizada, según los requerimientos de cada paciente y teniendo en cuenta la evidencia de mayor probabilidad de erradicación de la infección por H. pylori, así como la prevalencia de resistencia antibiótica de la zona geográfica y el perfil de susceptibilidad antimicrobiano.

Palabras clave: Helicobacter, Pylori, Esquemas, Tratamiento, Efectividad.

\section{ABSTRACT}

At present, Helicobacter pylori infection is still considered one of the chronic bacterial infections that occur most frequently in the world population. Likewise, it is recognized for the severity of its consequences and how complex its therapeutic management can be. The objective of this study is to capture the main treatment schemes for $\mathrm{H}$. pylori and their current effectiveness. Likewise, reference is made to antibiotic resistance, the situation in Ecuador and the possible treatment alternatives for the future. The research model is a bibliographic documentary type review. It was found that the treatment regimens classified according to the combination of drugs can be: quadruple, hybrid, concomitant and triple. While, depending on the time of their application, they can be classified into first, second, third and fourth line treatment. Quadruple therapy is considered one of the best initial therapies, especially in areas where the resistance rate to clarithromycin is> $15 \%$. For its part, hybrid therapy is $90 \%$ effective, even when compared to quadruple bismuth therapies. Some authors agree that concomitant therapy has an overall effectiveness of $88-90 \%$. Finally, the rate of resistance to clarithromycin has been increasing, which is why the failure of triple therapy is becoming increasingly likely. Consequently, each scheme should be chosen individually, according to the requirements of each patient and taking into account the evidence of a greater probability of eradication of $\mathrm{H}$. pylori infection, as well as the prevalence of antibiotic resistance in the geographical area and the profile. antimicrobial susceptibility.

Keywords: Helicobacter, Pylori, Schemes, Treatment, Effectiveness.

\section{RESUMO}

Actualmente, a infecção por Helicobacter pylori é ainda considerada uma das infecções bacterianas crónicas que ocorrem com mais frequência na população mundial. Do mesmo modo, é reconhecida pela gravidade das suas consequências e pela complexidade da sua gestão terapêutica. O objectivo deste estudo é captar os principais esquemas de tratamento da $\mathrm{H}$. pylori e a sua eficácia actual. Do mesmo modo, é feita referência à resistência aos antibióticos, à situação no Equador e às possíveis alternativas de tratamento para o futuro. O modelo de investigação é uma revisão bibliográfica de tipo documental. Verificou-se que os regimes de tratamento classificados de acordo com a combinação de fármacos podem ser: quádruplo, híbrido, concomitante e triplo. Enquanto que, dependendo do tempo da sua aplicação, podem ser classificados em tratamento de primeira, segunda, terceira e quarta linha. A terapia quádrupla é considerada uma das melhores terapias iniciais, especialmente em áreas onde a taxa de resistência à claritromicina é $>15 \%$. Por seu lado, a terapia híbrida é $90 \%$ eficaz, mesmo quando comparada com as terapias de bismuto quádruplo. Alguns autores concordam que a terapia concomitante tem uma eficácia global de 88-90\%. Finalmente, a taxa de resistência à claritromicina tem vindo a aumentar, e é por isso que o fracasso da terapia tripla está a tornar-se cada vez mais provável. Consequentemente, cada esquema deve ser escolhido individualmente, de acordo com os requisitos de cada paciente e tendo em conta a evidência de uma maior probabilidade de erradicação da infecção por $H$. pylori, bem como a prevalência da resistência aos antibióticos na área geográfica e o perfil. susceptibilidade antimicrobiana.

Palavras-chave: Helicobacter, Pylori, Esquemas, Tratamento, Eficácia. 


\section{Introducción}

En la actualidad, la infección por Helicobacter pylori, se sigue considerando una de las infecciones bacterianas crónicas que se presentan con mayor frecuencia en la población mundial. Asimismo, se reconoce por la severidad de sus consecuencias y lo complejo que puede ser su manejo terapéutico. No obstante, los avances científicos en torno a esta bacteria son de gran importancia para el manejo de su infección, siendo los más destacados en el ámbito del tratamiento médico.

El Helicobacter pylori $(\mathrm{H}$. pylori) "es un tipo de bacteria que causa infecciones en el estómago. Se encuentra, aproximadamente, en dos tercios de la población mundial. Es posible que se transmita por agua y alimentos contaminados, pero los investigadores no están seguros". (Enciclopedia Médica ADAM, 2020)

Es un patógeno gástrico común que causa gastritis, enfermedad ulcerosa péptica, adenocarcinoma gástrico y linfoma gástrico de bajo grado. La infección puede ser asintomática o provocar distintos grados de dispepsia. El diagnóstico se realiza mediante la prueba de urea en aire espirado, la prueba de antígeno en las heces y la investigación de muestras de biopsia endoscópica. (Vakil, 2020)

En muchos casos, la infección por Helicobacter pylori no presenta signos ni síntomas, es decir, la mayoría de las personas no se dan cuenta de que la tienen dado que no se enferman por ella. En consecuencia, cuando se manifiestan los signos y síntomas de la infección por helicobácter pylori, es probable que la infección ya haya ocasionado cualquiera de sus complicaciones, en cuyo caso los síntomas, por lo general, son los propios de la complicación. Entre estos síntomas tenemos:

- Dolor o ardor en el abdomen

- Dolor abdominal más agudo con el estó- mago vacío

- Náuseas

- Pérdida del apetito

- Eructos frecuentes

- Hinchazón

- Pérdida de peso involuntaria. (Clínica Mayo, 2020)

El Helicobacter pylori ha coexistido con el ser humano por miles de años y su infección es común. Los Centros para el Control y la Prevención de Enfermedades (CDC) de los Estados Unidos han calculado que "casi dos tercios de la población mundial albergan la bacteria, y los índices de infección son mucho más elevados en los países en desarrollo que en las naciones desarrolladas". En el año 1994, la Oficina Internacional de Investigación de Cáncer clasificó al $\mathrm{H}$. pylori como carcinógena, o causante de cáncer, en los humanos. (Instituto Nacional del Cáncer, 2013)

En cuanto a la prevalencia y la mortalidad de la infección por H. pylori (IHP) se explica lo siguiente:

Se estima una prevalencia promedio global de $44,3 \%$, pero oscilando entre $8,9 \%$ y $89,7 \%$ en distintas regiones internacionales, especialmente en relación con el estatus socioeconómico y las condiciones sanitarias y de urbanidad. La gran mayoría de la morbilidad asociada a la IHP deriva de esta tendencia a la cronificación; siendo clásicas en este sentido las patologías gastroduodenales, en particular relacionadas con la dispepsia, incluyendo gastritis, úlceras pépticas, enfermedad por reflujo gastroesofágico y el cáncer gástrico (CG). Este último es especialmente relevante, en tanto permanece como un problema prioritario para la salud pública mundial, actualmente correspondiendo al tercer lugar en mortalidad relacionada con cáncer, y siendo responsable por más de 700.00 muertes anualmente. Más allá de esto, la IHP se ha vinculado con 
varias otras complicaciones extragástricas, magnificando su impacto sobre la salud general. (Parra et al., 2020, p. 168)

Según Ford, Forman, \& Hunt, (2015) "los esquemas de tratamiento efectivos de la IHP pueden reducir la incidencia de cáncer gástrico, en particular en los habitantes con una alta prevalencia de infección con la bacteria, que también presentan un alto riesgo de cáncer gástrico". (p. 3)

En consecuencia, un efectivo tratamiento resulta fundamental para prevenir las complicaciones de la infección por Helicobacter pylori. El conocimiento de las terapias más actuales, así como de los estudios que demuestran su efectividad, le permiten al médico tratante, erradicar la infección y prevenir sus consecuencias más graves. En este orden de ideas, este material pretende ser una fuente útil para la consulta académica de estudiantes y profesionales de la salud. Asimismo, para pacientes y cuidadores.

El objetivo del presente estudio consiste en plasmar los principales esquemas de tratamiento del Helicobacter pylori y su efectividad en la actualidad. Asimismo, se hace referencia al problema que constituye la resistencia antibiótica para estos tratamientos, resistencia antibiótica en el Ecuador y las posibles alternativas de tratamiento para el futuro.

\section{Materiales y métodos}

El desarrollo del presente estudio se llevó a cabo bajo una metodología de tipo documental bibliográfica. En tal sentido, fueron ubicados archivos digitalizados, cuya búsqueda de contenidos científicos se llevó a cabo durante el mes de diciembre de 2020. Se formularon ecuaciones de búsqueda, con palabras clave, operadores lógicos y booleanos, en determinadas bases de datos y/o buscadores especializados, tales como: PubMed, SciELO, Researchgate, entre otros. Algunas de las formulaciones utilizadas con las que se obtuvieron mejores resultados fueron los siguientes: "he- licobacter pylori"; tratamiento de la infección por helicobacter pylori"; efectividad del tratamiento de helicobacter pylori". La información obtenida fue filtrada bajo los criterios de idioma (español); disponibilidad del contenido (completo); periodo de publicación (últimos 7 años), tipo de estudio: revisiones sistemáticas, de cohorte y de casos o de controles, informe de casos; y, clase de material bibliográfico (consensos, manuales, ensayos, tesis de grado, posgrado o doctorado, informes y otras clases de contenidos).

Asimismo, se seleccionaron los recursos antes mencionados en base a su producción, aval o promoción por parte de instituciones, entes, organizaciones, sociedades o asociaciones de profesionales en el área de la salud, de carácter público o privado, nacionales, internacionales o multilaterales con reconocimiento científico dentro de la comunidad de la salud. Por último, fueron desestimados aquellos contenidos repetidos (duplicados), editoriales, anotaciones académicas y otros tipos de materiales bibliográficos de escaso valor científico, con bajo nivel de evidencia o aportado por tratadistas sin acreditación en el área de la salud o medicina.

\section{Resultados}

El tratamiento para la erradicación del $\mathrm{H}$. pylori se lleva a cabo con múltiples medicamentos, por lo general, antibióticos más inhibidores de la secreción ácida. "Los inhibidores de la bomba de protones inhiben el H. pylori, y el mayor pH gástrico asociado con su uso puede aumentar la concentración tisular y la eficacia de los antimicrobianos, lo que crea un medio hostil para el $\mathrm{H}$. pylori". (Vakil, 2020)

Lo ideal es que el tratamiento de esta bacteria debería ser similar al de cualquier otra enfermedad de tipo infecciosa, basada en pruebas de susceptibilidad. No obstante, los cultivos de biopsias gástricas o métodos moleculares para investigar la susceptibilidad no se encuentran disponibles en 
todos los lugares del mundo, en virtud de lo cual, se inicia el tratamiento empíricamente. En estos casos es recomendable que se elijan las terapias teniendo en consideración el patrón de resistencia local a los antibióticos. Asimismo, resulta fundamental tomar en cuenta que la eficacia de los esquemas usados haya sido demostrada independientemente de consensos o guías internacionales. En cuanto a la eficacia de los tratamientos elegidos, estos deben tener una eficacia mínima del $90 \%$. Hasta la actualidad, ningún esquema de tratamiento para el H. pylori es $100 \%$ eficaz, por lo cual, en muchos casos son necesarios tratamientos de segunda y tercera línea, y de rescate o salvamento. (Morcillo, Otero, \& Gómez, 2018, p. 440, 441)

Según la combinación de fármacos los esquemas de tratamiento se clasifican en:

\section{Terapia cuádruple clásica}

Se considera una de las mejores terapias iniciales en áreas donde la tasa de resistencia a la claritromicina es $>15 \%$, tal y como sucede en muchos países desarrollados. En terapia cuádruple, se administran los siguientes medicamentos orales durante $10 \mathrm{a}$ 14 días:

- Un inhibidor de la bomba de protones (lansoprazol $30 \mathrm{mg} 2$ veces al día, omeprazol $20 \mathrm{mg} 2$ veces al día, pantoprazol $40 \mathrm{mg} 2$ veces al día, rabeprazol $20 \mathrm{mg}$ 2 veces al día o esomeprazol $40 \mathrm{mg} 1$ vez al día)

- Subsalicilato de bismuto (524 mg 4 veces al día)

- Metronidazol 250 mg 4 veces al día

- Tetraciclina 500 mg 4 veces al día. (Vakil, 2020)

\section{Terapia híbrida}

Consta de dos fases consecutivas de 7 días. En los primeros 7 días: inhibidor de la bomba de protones (IBP) + amoxicilina en dosis estándar u optimizadas (3 o 4 ve- ces al día) más IBP dos veces al día y en la última semana los medicamentos de la primera semana más dos antibióticos adicionales, usualmente claritomicina (500 mg) + Metronidazol/Tinidazol (500 mg), ambos dos veces al día. (Otero, Gómez, Otero, \& Trespalacios, 2018, p. 57)

En cuanto a la eficacia, Muñóz Gost, (2019) explica lo siguiente:

Existen diferentes estudios que muestran eficacia del tratamiento del $90 \%$, incluso comparándolos con terapias cuádruples con bismuto. Sin embargo, su efectividad podría verse disminuida por las resistencias a la claritromicina y metronidazol, y no se utiliza de manera generalizada. (p. 70)

Asimismo, Otero, Gómez, Otero, \& Trespalacios, (2018) refieren "una tasa de eficacia de $97 \%$. Cuando hay resistencia combinada a claritromicina y a metronidazol superior al 9\% (resistencia dual), la eficacia es menor al 90\%".

\section{Terapia concomitante}

La más usada es una combinación de IBP con amoxicilina, claritromicina y metronidazol. La razón para la recomendación de este esquema se debe a la resistencia dual (simultánea) para claritromicina y metronidazol. En consecuencia, "el metronidazol eliminará $\mathrm{H}$. pylori resistente a claritromicina $y$, al contrario, este eliminaría, las resistentes a metronidazol. Cuando hay resistencia dual, la eficacia disminuye notablemente". En cuanto a la eficacia los autores refieren que globalmente es de 88-90\%. (Otero, Gómez, Otero, \& Trespalacios, 2018, p. 57)

\section{Terapia triple estándar}

La triple terapia, anteriormente era el régimen recetado con mayor frecuencia para la infección por $\mathrm{H}$. pylori. Los siguientes fármacos orales se administran durante 10 a 14 días:

- Un inhibidor de la bomba de protones (lansoprazol 30 mg 2 veces al día, ome- 
prazol 20 mg 2 veces al día, pantoprazol 40 mg 2 veces al día, rabeprazol 20 mg 2 veces al día o esomeprazol 40 mg 1 vez al día)

- Amoxicilina (1 g por vía oral 2 veces al día) o metronidazol 250 mg 4 veces al día

- Claritromicina (500 mg por vía oral 2 veces al día). (Vakil, 2020)

El mismo autor refiere que, en diversas re(1) giones del mundo, la tasa de resistencia a la claritromicina ha ido en aumento, en razón de lo cual, se hace cada vez más probable el fracaso de la terapia triple. Por tal motivo, este régimen en la actualidad no es recomendado como terapia inicial, excepto en aquellos casos donde $\geq 85 \%$ de las cepas locales de $\mathrm{H}$. pylori sean susceptibles o que el régimen todavía sea clínicamente efectivo en el área local. "Para cepas de $\mathrm{H}$. pylori con resistencia a múltiples fármacos, la triple terapia con rifabutina parece ser efectiva".

Todos estos esquemas son aplicados en diferentes momentos, según sea necesario. Por cuanto ningún tratamiento es 100\% efectivo y la infección puede estar asociada a otras complicaciones y factores externos (resistencia antibiótica local, interrupción del tratamiento, entre otros), puede que estos esquemas que se apliquen en una primera línea (la primera vez que se administra el tratamiento) no sean efectivos, en cuyo caso se requiere de una segunda, tercera y hasta cuarta línea, los cuales veremos a continuación.

Según el momento en que se aplica el tratamiento, estos esquemas pueden ser:

\section{Tratamiento de primera línea}

Para Avalos, Vanterpool, Morales, Lamoth, \& Prendes, (2019) como tratamiento de primera línea de la infección se recomienda, con base a lo estipulado por la IV Conferencia española de consenso sobre el tratamiento de la infección por Helicobacter pylori, una pauta cuádruple concomitante sin bismuto (IBP, claritromicina, amoxicilina y metronidazol). La elección de este esquema dependerá primordialmente de la tasa de resistencia de esta bacteria a los antibióticos prescritos. Es importante destacar, que no es recomendable la terapia triple clásica (IBP, claritromicina y amoxicilina) como tratamiento de primera línea, cuando la tasa de resistencia a la erradicación es inaceptablemente baja. (p. 985)

\section{Efectividad}

En cuanto a la efectividad de este tratamiento de primera línea, estos autores agregan:

Además de la resistencia antibiótica, otros factores que influyen sobre la eficacia del tratamiento erradicador son el cumplimiento por parte del paciente y su historial previo de consumo de antibióticos, que podría condicionar la elección de la primera opción terapéutica. La terapia cuádruple con bismuto (IBP, bismuto, tetraciclina y metronidazol) podría ser una alternativa válida al tratamiento cuádruple sin bismuto, dado que está constituida por fármacos, como el bismuto y tetraciclina frente a los que el $\mathrm{H}$. pylori por sí solo, es resistente. Un reciente ensayo multicéntrico europeo demostró buenos resultados con Pylera (una cápsula que contiene bismuto, tetraciclina y metronidazol) administrado durante 10 días, alcanzando una eficacia (confirmada mediante una única prueba del aliento) del 90\% (significativamente superior a la de la terapia triple). (p. 985)

Por otra parte, Paz, Florez, Lasa, \& Zubiaurre, (2020) en su trabajo titulado "Infección por Helicobacter pylori. Frecuencia del fracaso del tratamiento de primera línea", Ilevaron a cabo un estudio observacional de tipo corte transversal retrospectivo en el Servicio de Gastroenterología del Hospital Británico, en el período enero 2015 a julio 2017, en 81 pacientes con gastritis por esta bacteria, se plantearon investigar factores asociados a la persistencia de Helicobacter pylori postratamiento antibiótico. Con base a los resultados obtenidos concluyeron lo siguiente: 
...identificamos que el fracaso terapéutico en pacientes con infección por $\mathrm{H}$. pylori tratados por primera vez es mayor al $17 \%$ y que el predictor independiente asociado al riesgo de fracaso terapéutico es el uso del esquema triple con claritromicina. Por lo tanto, dicho esquema debería ser evitado en nuestro medio. (p. 115, 116)

\section{Tratamiento de segunda y tercera línea}

Con respecto a este esquema, Morcillo, Otero, \& Gómez, (2018) refieren que cuando fracasa el tratamiento de primera línea, se debe aplicar el de segunda línea, el cual es elegido entre cualquiera de los esquemas que no tengan los antibióticos que se usaron en la de primera línea. Igualmente, se eligen los tratamientos de tercera línea. Otras terapias elegibles pueden ser la cuádruple clásica, concomitantes o híbridas. (p. 441)

\section{Tratamiento de rescate, salvamento o cuarta línea}

Para Otero, Gómez, Otero, \& Trespalacios, (2018) estos tratamientos de cuarta línea, se administran en los casos en que tres tratamientos previos han fallado. Generalmente, los antibióticos para estos esquemas son furazolidona o rifabutina. La furazolidona es un inhibidor de la mono amino oxidasa, altamente eficaz contra diversos microrganismos, es económico, no obstante, se encuentra disponible en muy pocos países. "La dosis recomendada es 100 mg tres veces al día por 14 días. Se utiliza en terapias cuádruples con bismuto (2 a 4 veces al día) con amoxicilina o tetraciclina más IBP". ( $p$. 58-59)

\section{Eficacia}

Hace dos décadas en Colombia, se utilizó este medicamento en terapia cuádruple por 14 días y la tasa de erradicación fue de 86\% (IC95\% 65-94\%) con amoxicilina, esto según el estudio de Segura et al., citado por Otero, Gómez, Otero, \& Trespalacios, (2018). Asimismo, los autores refieren a Otero et al. quienes encontraron en su estudio una efectividad de $91 \%$ con tetraciclina en la erradicación de H. pylori. Por otro lado, refieren a Liang et al. para explicar que, en un reciente estudio de China, durante 14 días de furazolidona (100 mg 3 veces al día) con amoxicilina (1 gr 3 v/día), Citrato de Bismuto (220 mg 2 v/día) y lansoprazol (30 mg 2 v/ día), la eficacia por ITT fue 95,2\% (IC95\% 91,1-99,3\%) y PP 99\% (IC95\% 97,0-100\%). No obstante, su eficacia, la furazolidona, es subutilizada, posiblemente por el temor a efectos adversos. Además, se ha especulado que podría tener efectos oncogénicos, sin embargo, no hay evidencias de posibilidad. Estudios más recientes han ratificado su seguridad. (p. 59)

\section{Resistencia antibiótica}

En cuanto al problema que representa la resistencia antibiótica para el tratamiento $\mathrm{Pa}-$ rra et al., (2020) refieren lo siguiente:

La resistencia antibiótica del $\mathrm{H}$. pylori se ha convertido en un problema de envergadura abismal. Esta crisis ha sido reconocida por la Organización Mundial de la Salud (OMS), la cual en el año 2017 agregó este problema a la lista de prioridades para el desarrollo de antibióticos para bacterias resistentes. La frecuencia de la resistencia a distintos antibióticos varía ampliamente entre regiones geográficas. En una revisión sistemática y meta-análisis de Savoldi y cols. que incluyó 178 estudios provenientes de 65 países, se consiguió que la prevalencia de la resistencia primaria a la claritromicina, metronidazol y levofloxacina es mayor al $15 \%$ en todas las regiones internacionales establecidas por la OMS, a excepción de la resistencia primaria a la claritromicina en las Américas y la región del Asia Sureste; y la resistencia primaria a la levofloxacina en la región europea. No obstante, debe siempre primar la consideración de la resistencia antimicrobiana en regiones locales más delimitadas o específicas. (p. 169) 
En los últimos años, el aumento de la prevalencia de cepas de $\mathrm{H}$. pylori resistentes a los antibióticos ha llevado a una reducción en el éxito de los tratamientos clásicos: inhibidor de la bomba de protones (IBP) más dos de los siguientes antibióticos: claritromicina (CLA), amoxicilina (AMO) o metronidazol (MTZ) durante 7- 10 días. Este esquema de tratamiento se ha vuelto menos efectivo. Algunos estudios indican una tasa de erradicación menor al $50 \%$ de los casos. (Avalos, Vanterpool, Morales, Lamoth, \& Prendes, 2019, p. 982)

\section{Resistencia antibiótica. Situación en el Ecuador}

La bacteria Helicobacter Pylori, aproximadamente está presente en la mitad de la población de todo el mundo. Principalmente en países en desarrollo estas cifras pueden llegar a ser más elevadas. Sempertegui citado por Espinoza Jumbo, (2017) refiere que en el Ecuador la tasa de infección por esta bacteria se encuentra en un $93.2 \%$ de la población. (p. 30)

En el Ecuador como en la mayoría de las regiones del mundo, puede utilizarse cualquiera de los esquemas de tratamiento antes mencionados para erradicar el $\mathrm{H}$. pylori. En muchas regiones se encuentran disponibles los 5 antibióticos básicos para incluir y combinar en el esquema elegido (metronidazol, claritromicina, amoxicilina, tetraciclina y levofloxacina). Uno de los factores más importantes para considerar en la elección del tratamiento es el relacionado con la resistencia antibiótica, el cual resulta determinante para alcanzar la efectividad del tratamiento y la erradicación de esta bacteria. En consecuencia, se resumen a continuación algunos estudios y consideraciones relacionados con este factor en el Ecuador.

Reyes et al., (2017) llevaron a cabo un estudio donde se determinó la susceptibilidad a 5 antibióticos (metronidazol, claritromicina, amoxicilina, tetraciclina y levofloxacina) utilizados en la terapia de erradicación de $\mathrm{H}$. pylori aislado de una población adulta con dispepsia recurrente en Quito, Ecuador, donde obtuvieron los siguientes resultados:

El mayor número de cepas que presentaron concentración mínima inhibitoria (CMI) superiores a los valores de referencia fueron para metronidazol y claritromicina, mientras que el análisis de asociación de antibióticos para los distintos esquemas terapéuticos demostró que el $32 \%$ de los aislados fue resistente a la combinación amoxicilina/ claritromicina y un $42 \%$ a la claritromicina/ metronidazol. (p. 307)

Asimismo, los autores discutieron que los valores encontrados en su estudio, donde un $66 \%$ de los aislados presentaba resistencia, se ubicaban muy por encima del $12 \%$ reportado para América Latina y del 9,5\% reportado para el Ecuador en el año 2003. por otra parte, en cuanto a la amoxicilina estos encontraron que el $43 \%$ de cepas presentó una $\mathrm{CMI} \geq 0,125$, clasificadas como resistentes, lo que representa un porcentaje alto tomando en consideración que para América Latina esta resistencia se encuentra entre 0\%-39\%; y aún más por encima de los valores registrados para el Ecuador en años anteriores que no superaba el $4 \%$. Para el metronidazol encontraron una resistencia del $63 \%$ lo que se ubica dentro del rango reportado para América Latina que va de un 12,5\%-95\% y para el Ecuador que registraba un $80,9 \%$. En cuanto a la combinación de 2 antibióticos usados para la terapia de erradicación, se encontró que más de 30\% de cepas presenta resistencia simultáneamente, sea claritromicina o levofloxacina. Los autores concluyeron que existe un aumento en la resistencia a dichos antibióticos en Ecuador a lo largo del tiempo y recomendaron el análisis riesgo/ beneficio cuando se utilice la claritromicina o amoxicilina como tratamiento empírico en pacientes con dispepsia recurrentes o que posiblemente ya recibieron tratamiento previo, junto con la realización de pruebas de susceptibilidad, para minimizar el riesgo de fallo terapéutico. (p. 307, 308) 
Por otra parte, el estudio de Guzmán Guerrero, (2016) para determinar el porcentaje de resistencia a la claritromicina de cepas de Helicobacter pylori a través de biopsias gástricas obtenidas mediante técnicas fenotípica (E-test) y presencia de mutaciones puntuales por técnicas moleculares (reacción en cadena de la polimerasa, PCR) y secuenciación del ADN en el Hospital Eugenio Espejo y Hospital de las Fuerzas Armadas, Quito, Ecuador, durante julio-diciembre del 2015, encontró que "la resistencia a la claritromicina presente en las cepas aisladas provenientes de las biopsias gástricas es de $67,9 \%$, con presencia de 3 cepas intermedias. La mayoría de cepas in vitro presentan un MIC > $256 \mu \mathrm{g} / \mathrm{ml}$ ". Asimismo, en base a su hallazgo y disertación, plasmó algunas recomendaciones, entre las que destacamos las siguientes:

Ampliar el estudio de la resistencia a la claritromicina, debido a que los valores de susceptibilidad pueden variar en las diferentes zonas geográficas o regiones del mismo país, como se observa en estudios realizados en América Latina, razón por lo que podría estar fallando el tratamiento de erradicación. Es recomendable que los médicos antes de dar un segundo tratamiento de erradicación, si el primero ha fallado consideren la prevalencia de la región ante el perfil de susceptibilidad antimicrobiana, y como lo especifica el Consenso de Maastricht IV se realice el cultivo o pruebas moleculares para detectar la resistencia a la claritromicina. (p. 61)

En cuanto a la efectividad de la terapia triple estándar con claritromicina como tratamiento de primera línea, Sierra, Forero, \& Rey, (2014) refieren en su revisión sistemática que, de los experimentos clínicos aleatorizados latinoamericanos incluidos se obtuvieron algunas tasas de erradicación de dicha terapia, entre las que destacan el Ecuador con 7 versus 10 días, del 68.3 y del $83.8 \%$. Ubicándose entre los países con tasas subóptimas de erradicación con este esquema. Asimismo, los autores concluyeron:
La eficacia de las diversas estrategias de tratamiento disponibles varía significativamente dentro de las diferentes regiones, como es el caso de la triple terapia estándar, la cual sigue siendo ineficaz en países con cepas resistentes, principalmente a agentes como la claritromicina y el metronidazol, por lo cual esta terapia no sería aceptable como terapia empírica. $(44,46)$

\section{Posibles alternativas para el tratamiento del Helicobacter pylori}

En la actualidad, gracias a los adelantos en la tecnología y los estudios de investigación, se encuentran múltiples terapias para el tratamiento de Helicobacter pylori, algunos disponibles y otros en desarrollo. No obstante, es necesario la combinación de estas terapias emergentes con las clásicas, por cuanto por sí mismas son incapaces de combatir esta bacteria.

Una de estas terapias alternativas para Herráez López, (2018) lo constituye un nuevo fármaco, el cual en un futuro podría ser incluido en un esquema de erradicación de $\mathrm{H}$. pylori, se trata del vonoprazan. El vonoprazan "es un inhibidor reversible de la bomba ATPasa $\mathrm{H}+/ \mathrm{K}+$; por lo tanto, actuaría disminuyendo el nivel de ácido en el estómago lo que contribuye a la disminución de la carga bacteriana y aumenta la eficacia de la terapia antibiótica, como se ha explicado anteriormente". Por otra parte, el mismo autor refiere que otra forma de poder combatir esta infección puede ser por medio de la administración de vacunas, no obstante, esta alternativa se encuentra en desarrollo. (p. 17)

Asimismo, en los últimos años se ha propuesto el uso de probióticos, Según la OMS los probióticos son microrganismos vivos que, administrados en dosis adecuadas, producen efectos benéficos. En erradicación de $\mathrm{H}$. pylori, la adición de probióticos tiene la finalidad de disminuir efectos adversos y mejorar la eficacia, sin embargo, hay controversia sobre su utilidad. (Otero, Gómez, Otero, \& Trespalacios, 2018, p. 59) 


\section{Efectividad}

Con respecto al vonoprazan, en la actualidad este fármaco sólo se encuentra disponible en Japón y Corea, sin embargo, se espera que pronto esté disponible en otros países. "Este nuevo fármaco ha demostrado recientemente conseguir una supresión ácida inmediata, potente y sostenida comparada con el esomeprazol y rabeprazol". (Avalos, Vanterpool, Morales, Lamoth, \& Prendes, 2019, p. 984)

En cuanto a la efectividad de los probióticos, Gutiérrez Colino, (2019) manifiesta lo siguiente:

Las pruebas actuales indican que la administración de suplementos probióticos durante el tratamiento de erradicación de Helicobacter pylori puede aumentar las tasas de erradicación y disminuir la incidencia general de eventos adversos relacionados con el tratamiento y la incidencia de algunos síntomas gastrointestinales específicos. Sin embargo, los resultados deben interpretarse con cautela debido a la presencia de heterogeneidad entre los ensayos incluidos en el análisis. Los estudios futuros deben centrarse en aclarar qué cepas de probióticos, dosis y períodos de tratamiento son óptimos para los pacientes con infección por H. pylori. (p. 12)

Con relación a la eficacia de algunas pruebas de vacunas, en el año 2015, un estudio realizado en China mostró buenos resultados; posterior a la administración de tres dosis orales de una ureasa de $\mathrm{H}$. pylori fusionada con un adyuvante a una población adolescente, los resultados fueron de una prevención de más del $70 \%$ de las infecciones esperadas en un año. "Si la vacuna resultase eficaz, podría resolver el problema de la resistencia bacteriana y eliminar la enfermedad asociada a $\mathrm{H}$. pylori de forma completa". (Herráez López, 2018, p. 17)

\section{Conclusiones}

Existen diversos esquemas de tratamiento para erradicar el Helicobacter pylori, no obstante, no existe eficacia de $100 \%$ en ninguno de ellos. Para la elección de estos esquemas debe considerarse la tasa de resistencia local antimicrobiana y la exposición previa a los antibióticos por parte del paciente.

Existen factores que pueden disminuir o aumentar la efectividad de los esquemas de tratamiento. En el primero de los casos, la resistencia antibiótica y la falta de continuidad del tratamiento por parte del paciente pueden disminuir la efectividad del mismo. Por otra parte, la adherencia al tratamiento con supresión ácida potente y una duración más prolongada (14 días) en el tratamiento contribuyen a aumentar la tasa de efectividad del esquema.

La terapia cuádruple es considerada una de las mejores terapias iniciales, especialmente en áreas donde la tasa de resistencia a la claritromicina es $>15 \%$. La terapia híbrida tiene una eficacia del 90\%, incluso comparándolos con terapias cuádruples con bismuto. Sin embargo, su efectividad podría verse disminuida por las resistencias a la claritromicina y metronidazol, y no se utiliza de manera generalizada. En el caso de la terapia concomitante algunos autores coinciden en que tiene una efectividad global de $88-90 \%$. Por último, en cuanto a la terapia triple, la tasa de resistencia a la claritromicina ha ido en aumento, razón por la cual se hace cada vez más probable el fracaso de este esquema.

En consecuencia, cada esquema debe elegirse de manera individualizada, según los requerimientos de cada paciente y teniendo en cuenta la evidencia de mayor probabilidad de erradicación de la infección por $\mathrm{H}$. pylori, así como la prevalencia de resistencia antibiótica de la zona geográfica y el perfil de susceptibilidad antimicrobiano.

\section{Bibliografía}

Avalos, R., Vanterpool, M., Morales, M., Lamoth, I., \& Prendes, A. (2019). Nuevos retos en el tratamiento de la infección por Helicobacter pylori. Revista Médica Electrónica, 41(4), 979-992. Recuperado 
el 19 de Diciembre de 2020, de https://www.medigraphic.com/pdfs/revmedele/me-2019/me194l. pdf

Clínica Mayo. (08 de Abril de 2020). Clínica Mayo. Recuperado el 06 de Diciembre de 2020, de https://www.mayoclinic.org/es-es/diseases-conditions/h-pylori/symptoms-causes/syc-20356171

Enciclopedia Médica ADAM. (03 de Diciembre de 2020). MedlinePlus. Recuperado el 05 de Diciembre de 2020, de https://medlineplus.gov/spanish/ helicobacterpyloriinfections.html

Espinoza Jumbo, K. J. (2017). Eficacia del tratamiento para erradicación de Helicobacter Pylori, esquema doble vs. esquema triple, aplicado a pacientes que asisten a la Clínica de Especialidades Mogrovejo. Tesis previa a la obtención del título de médico general, Universidad de Loja, Facultad de la Salud Humana, Loja. Recuperado el 30 de Diciembre de 2020, de https://dspace.unl.edu.ec/ jspui/bitstream/123456789/19423/1/Karin\%20Jeanette\%20Espinoza\%20Jumbo.pdf

Ford, A. C., Forman, D., \& Hunt, R. (22 de Julio de 2015). Erradicación del Helicobacter pylori para la prevención del cáncer gástrico. Cochrane Database of Systematic Reviews, 7, 1-12. doi:https:// doi.org/10.1002/14651858.CD005583.pub2

Gutiérrez Colino, B. (2019). Helicobacter pylori: nuevos tratamientos. Tesis de Grado, Universidad Complutense, Facultad de Farmacia, Madrid. Recuperado el 20 de Diciembre de 2020, de http://147.96.70.122/Web/TFG/TFG/Memoria/BEATRIZ\%20GUTIERREZ\%20COLINO.pdf

Guzmán Guerrero, K. V. (2016). Determinación de la resistencia a la claritromicina como fármaco de primera línea, en aislamientos de Helicobacter pylori provenientes de biopsias gástricas del Hospital Eugenio Espejo y Hospital de las Fuerzas Armadas $N^{\circ} 1$, mediante técnicas fenotípica.. Disertación Previa a la obtención del Título de Bioquímica Clínica, Pontificia Universidad Católica del Ecuador, Escuela de Bioanálisis, Quito. Recuperado el 29 de Diciembre de 2020, de http://repositorio.puce. edu.ec/bitstream/handle/22000/12526/TESIS\%20 H.\%20pylori\%20GUZMAN\%20K..pdf?sequen$\mathrm{ce}=1 \&$ is Allowed $=\mathrm{y}$

Herráez López, Á. (2018). Resistencia a antibióticos en Helicobacter pylori. Tesis de Grado, Universidad complutense de Madrid, Facultad de Farmacia, Madrid. Recuperado el 18 de Diciembre de 2020, de http://147.96.70.122/Web/TFG/TFG/Memoria/ANGELA\%2OHERRAEZ\%20LOPEZ.pdf

Instituto Nacional del Cáncer. (05 de Septiembre de 2013). Recuperado el 06 de Diciembre de 2020, de https://www.cancer.gov/espanol/cancer/causas-prevencion/riesgo/germenes-infecciosos/hoja-informativa-h-pylori

Morcillo, J., Otero, W., \& Gómez, M. (2018). Helicobacter pylori: ¿cómo mejorar las terapias de erradicación? Revista Colombiana de Gastroenterología, 33(4), 437-447. doi:http://dx.doi. org/10.22516/25007440.314

Muñóz Gost, N. (2019). Helicobacter pylori y Medicina basada en la evidencia. Tesis de Doctorado, Universidad Autónoma de Barcelona, Departamento de Medicina, Barcelona. Recuperado el 28 de Diciembre de 2020, de https://www.tdx.cat/ bitstream/handle/10803/667358/nmg1de1.pdf?sequence $=1$ \&is Allowed $=y$

Otero, W., Gómez, M., Otero, L., \& Trespalacios, A. (2018). Helicobacter pylori: ¿cómo se trata en el 2018? Gastroenterología Perú, 38(1), 54-63. Recuperado el 23 de Diciembre de 2020, de http:// www.scielo.org.pe/pdf/rgp/v38n1/a09v38n1.pdf

Parra, J., Córdoba, A., Mancero, M., Flores, B., Ormaza, J., Reyes, R., . . Santos, V. (02 de Marzo de 2020). Aproximación actual a la infección por Helicobacter pylori. Archivos Venezolanos de Farmacología y Terapéutica (AVFT), 39(2), 167-171. Recuperado el 15 de Diciembre de 2020, de https://www.revistaavft.com/images/revistas/2020/ avft_2_2020/4_aproximacion.pdf

Paz, S., Florez, L., Lasa, J., \& Zubiaurre, I. (2020). Infección por Helicobacter pylori. Frecuencia del fracaso del tratamiento de primera línea. Medicina (Buenos Aires), 80(2), 111-116. Recuperado el 23 de Diciembre de 2020, de https://www.medicinabuenosaires.com/revistas/vol80-20/n2/111.pdf

Reyes, J., Guzmán, K., Morales, E., Villacís, J., Pasmiño, G., Pacheco, R., \& Escalante, L. (2017). Susceptibilidad antibiótica de Helicobacter pylori: un estudio de prevalencia en pacientes con dispepsia en Quito, Ecuador. Revista colombiana de Gastroenterología, 32(4), 305-310. doi:DOI: https://doi. org/10.22516/25007440.173

Sierra, F., Forero, J. D., \& Rey, M. (2014). Tratamiento ideal del Helicobacter pylori: una revisión sistemática. Revista de Gastroenterología de México, 79(1), 28-49. Recuperado el 29 de Diciembre de 2020, de https://www.sciencedirect.com/science/ article/pii/S0375090613000517

Vakil, N. (Enero de 2020). Manuales MSD. Recuperado el 05 de Diciembre de 2020, de https://www. merckmanuals.com/es-us/professional/trastornos-gastrointestinales/gastritis-y-enfermedad-ulcerosa-p\%C3\%A9ptica/infecci\%C3\%B3n-por-helicobacter-pylori 


\section{CITAR ESTE ARTICULO:}

Lara Icaza, J. D., Triana Castro, T., \& Fuenmayor Boscán, A. (2020). Helicobacter Pylori, esquemas de tratamiento y su efectividad en la actualidad. RECIAMUC, 4(4 (esp), 113-124. https://doi.org/10.26820/reciamuc/4.(4).diciembre.2020.113-124

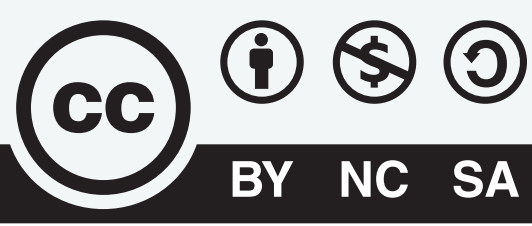

CREATIVE COMMONS RECONOCIMIENTO-NOCOMERCIAL-COMPARTIRIGUAL 4.0. 